\title{
Demandas contemporâneas da psicologia no setor público: reflexões winnicottianas sobre a tendência antissocial
}

\author{
Contemporary demands of psychology in the public sector: \\ Winnicott reflections on the antisocial tendency
}

\author{
Diana Pancini de Sá Antunes Ribeiro'; Ana Lúcia Volpato²; Jorge Luis Ferreira Abrão³
}

\section{Resumo}

O presente artigo objetiva uma reflexão sobre a demanda contemporânea para psicologia em serviços públicos de saúde, especialmente aquela que se refere às crianças e adolescentes, e seus responsáveis, em que o conceito de tendência antissocial é a queixa principal. Para alcançar o desenvolvimento da presente reflexão utilizou-se da metodologia psicanalítica, de forma que práticas de um projeto de extensão universitária permitiram a compreensão psicanalítica do conceito de tendência antissocial e sua repercussão na atualidade da saúde coletiva. A partir desta metodologia sustenta-se a discussão deste trabalho no conceito de tendência antissocial de Winnicott e de um breve histórico sobre a inserção da psicologia no setor público, além da apresentação da proposta do projeto de extensão universitária. Desta forma, os resultados indicam a possibilidade de se construírem enquadres clínicos outros que não somente o da psicoterapia em setting individual para manifestações de tendência antissocial em crianças e adolescentes considerados antissociais. Após análise do conceito, da inserção de psicólogos na saúde pública e dos enquadres clínicos propostos pelo projeto de extensão universitária, conclui-se pela pertinência de um olhar psicanalítico winnicottiano, no qual $\mathrm{o}$ ambiente seja considerado no tratamento oferecido às crianças e adolescentes considerados antissociais.

Palavras-chaves: Psicanálise. Winnicott. Tendência antisocial. Serviço público de saúde.

\begin{abstract}
The purpose of this article is reflect the contemporary demand for psychology in public health services, especially that refer to children and adolescents, and their guardians, in which the concept of antisocial tendency is the main complaint. To achieve the development of this reflection, we used the psychoanalytic methodology, so that practices of a university extension project allowed the psychoanalytic understanding of the concept of antisocial tendency and its impact on today's public health. From this methodology, the discussion of this work is supported from the concept of antisocial tendency, by Winnicott, and a brief history of the insertion of psychology in the public health, besides the presentation of the university extension project. Thus, the results indicate the possibility of constructing clinical different framings of the psychotherapy in individual setting to manifestations of antisocial tendency in children and adolescents considered antisocial. After the analysis of the concept, of the insertion of psychologists in public health and of the clinical framings proposed by the university extension project, was concluded by the need for a look of psychoanalysis by Winnicott in which the environment is considered in the treatment offered to children and adolescents considered antisocial.
\end{abstract}

keywords: Psychoanalysis. Winnicott. Antisocial tendency. Public health service.

\footnotetext{
${ }^{1}$ Doutora em Psicologia como Profissão e Ciência. Professor Assistente Doutor junto ao Departamento de Psicologia Clínica na Universidade Estadual Paulista Júlio de Mesquita Filho. E-mail: dianapsar@hotmail.com

${ }^{2}$ Mestre em Psicologia, pela Universidade Estadual Paulista Júlio de Mesquita Filho (UNESP - Assis). E-mail: anavolpato_psic@ yahoo.com.br

3 Doutor em Psicologia pela Universidade de São Paulo (USP/SP). Livre-Docente e Professor Adjunto do Departamento de Psicologia Clínica da Faculdade de Ciências e Letras de Assis da Universidade Estadual Paulista (UNESP)
} 


\section{Introdução}

Com o objetivo principal de reflexão sobre a demanda contemporânea para psicologia em serviços públicos de saúde - especialmente aquelas que se referem às crianças e adolescentes, e seus responsáveis, em que o conceito de tendência antissocial é a queixa principal - faz-se necessário, primeiramente, uma concisa exposição do conceito de tendência antissocial apresentado por Donald Woods Winnicott (1896-1971). Após, para que se possa entender como a saúde mental infantil é tratada nos setores públicos de saúde, é necessário que se faça, ainda, um breve resgate histórico da própria saúde pública ${ }^{4}$ no Brasil. Apresenta-se, na sequência, um projeto de extensão universitária ${ }^{5}$ coordenado por um dos autores deste trabalho a fim de problematizar a questão de acolhimento psicológico às queixas citadas sob outro ponto de vista que não o da psicoterapia tradicional.

Para a reflexão dessas demandas contemporâneas, utilizou-se da metodologia de pesquisa psicanalítica. Segundo Freud (1996, p. 253), “psicanálise é o nome de (1) um procedimento para investigação de processos mentais [...], (2) um método (baseado nessa investigação) [...] e (3) uma coleção de informações psicológicas [...]". Sobre essa questão, Herrmann $(1989$, p. 18) afirma que o método psicanalítico diz respeito à interpretação, pois "se aceitarmos que as nossas são teorias interpretativas [...], teremos como decorrência imediata sua dependência para com o método da Psicanálise, o método interpretativo".

Resende (1993), vai ao encontro dessas ideias pois acredita na existência da relação entre a psicanálise com a exegese, hermenêutica e interpretação. Emídio (2010) concorda e explica essa ideia sobre a função do exegeta, o qual buscaria o sentido do texto através do próprio texto, é “o exercício da pesquisa na biblioteca" (EMÍDIO, 2010, p. 17). Na função do hermeneuta, o pesquisador se envolveria com o texto, pensaria sobre ele e o interpretaria para além do escrito, utilizando-se uma vivência a partir do texto. Já o pesquisador enquanto intérprete seria capaz de "dar sentido [...] aos fenômenos psicanalíticos" (EMÍDIO, 2010, p. 17).

Utilizou-se dessas três funções enquanto pesquisador uma vez que foi necessário tanto o embasamento teórico psicanalítico (exegeta), quanto foi necessário vivenciar experiências dentro da rede pública de saúde (hermeneuta). Além disso, a função do pesquisador-interprete, ou seja, o pesquisador que se utiliza da interpretação, tal como apontado por Herrmann (1989), também se fez presente na medida em que se pôde compreender e dar sentido aos fenômenos psicanalíticos, especialmente àqueles referentes a queixas de tendência antissocial, abarcados pelo projeto mencionado.

A psicanálise pensada por Donald Woods Winnicott embasará, assim, a análise que aqui se realiza. Trata-se do uso da psicanálise winnicottiana para o direcionamento de um pensamento clínico que leve em conta o que este autor denominou de 'Teoria do desenvolvimento emocional' e que alguns autores contemporâneos denominam de 'Teoria do amadurecimento de Winnicott' (DIAS, 2009). Para melhor compreensão do conceito de tendência antissocial deste autor, sua teoria do amadurecimento pessoal também é brevemente apresentada ao se discorrer sobre tendência antissocial.

\section{A Tendência Antissocial em Winnicott}

Para Winnicott, a tendência antissocial não é um diagnóstico, podendo ser encontrada em pessoas ditas normais ou em neuróticos ou psicóticos, crianças,

\footnotetext{
${ }^{4}$ Embora saibamos da construção do termo saúde coletiva pelas implicações das políticas e práticas dos profissionais nos espaços públicos de atendimento à saúde, optamos por não entrarmos neste mérito e usar saúde pública pela constituição histórica dada a esta na implementação do SUS.

${ }^{5}$ Projeto 'Enquadres clínicos winnicottianos na saúde pública', sob coordenação da Dra Diana Pancini de Sá Antunes Ribeiro.
} 
adolescentes e adultos (WINNICOTT, D., 2005b). Tal como Winnicott o fez, este artigo se refere à criança apenas por uma questão de simplicidade. E também utiliza o conceito tal como trabalhado por Winnicott, embora ele próprio reconheça a participação de outros psicanalistas em sua construção.

O conceito de tendência antissocial surge no período da Segunda Guerra Mundial, quando Winnicott assumiu um cargo como psiquiatra do Plano de Evacuação Governamental da Inglaterra. Este plano versava sobre a retirada de crianças próximas ao front de batalhas, portanto expostas aos perigos da guerra, levadas para o interior do país e acomodadas em lares adotivos provisórios ou alojamentos coletivos. O efeito causado pela separação de seus pais biológicos e de outras perdas sofridas pelas crianças evacuadas possibilitou que Winnicott refletisse sobre a privação, a delinquência e a tendência antissocial apresentada por estas crianças (WINNICOTT, C., 2005).

Segundo Silva, Gregio e Ribeiro (2011, p. 153) a psicanálise até então “[...] entendia a criminalidade e a delinquência como frutos da ambivalência inconsciente, depositando todas suas origens no mundo interior do indivíduo". Winnicott (2000a) considera esta questão, mas amplia sua teoria do amadurecimento pessoal após as experiências em tempos de guerra e acrescenta o fator ambiental como sendo de extrema importância na raiz da tendência antissocial.

Nesta experiência, Winnicott observou os efeitos que a separação criança-família provocava nas crianças, constatando que esta desenvolvia sérios problemas psicológicos, especialmente quando se tratava de crianças muito pequenas, entre dois e cinco anos. Quanto mais tempo as crianças pequenas ficavam afastadas de sua família de origem, mais comportamentos antissociais apresentavam, podendo-se observar atos delinquenciais. Tal fato levou Winnicott a considerar que as origens da tendência antissocial podem ser atribuídas a esse tipo de privação, que ele passa a denominar de-privação (WINNICOTT, D., 2005b).

Os comportamentos antissociais solicitavam a administração das equipes que trabalhavam com as crianças em alojamentos e a proposta de Winnicott era o oferecimento de um ambiente continente e acolhedor aos evacuados, para que restabelecessem parte da segurança perdida no cenário hostil da guerra (WINNICOTT, C., 2005). Para compreender esta proposta de Winnicott reportar-se-á à natureza da tendência antissocial, a partir de sua teoria do amadurecimento.

Para Winnicott, o ser humano nasce com uma tendência inata ao amadurecimento e à integração (DIAS, 2009). Inicialmente somos totalmente dependentes do meio e este período é por ele denominado de dependência absoluta. O bebê quando nasce depende da mãe (ou substituto materno) para sua sobrevivência e esta, neste período, deve estar totalmente voltada a satisfazer as necessidades de seu filho, de modo que, o seio (ou a mamadeira) é sempre oferecido ao bebê no momento em que este está pronto para 'criá-lo' e 'encontrá-lo'. Esta experiência permite ao bebê ter a ilusão de que o seio faz parte dele, de seu controle mágico, onipotente. E esta mãe é considerada suficientemente boa ${ }^{6}$.

Winnicott denomina de preocupação materna primária o estado de ser da mulher, que se inicia no final da gestação e persiste semanas ou meses após o parto, no qual a sensibilidade da mulher é intensificada, sendo comparada a uma condição doentia. Winnicott refere-se à palavra doença, pois

\footnotetext{
${ }^{6}$ A mãe suficientemente boa, neste período, é aquela que cuida da criança nas ocasiões de calma, bem como nas situações de tensão pulsional. A mãe ou seu substituto também auxilia a criança a lidar com a relação de excitação que, se tudo correr bem, faz com que ela entre em contato com a culpa, necessidade de reparação e angústia depressiva. O modo como a mãe, ou quem realiza a função de maternagem, faz a assistência no cuidado e a apresentação gradual do mundo para a criança determinará a estruturação da vida psíquica e suas relações com outros objetos (WINNICOTT, 1996).
} 
compreende que somente as mulheres saudáveis são capazes de adoecer nesse estado e posteriormente recuperar-se dele - à medida em que o bebê solicitála e o ambiente à sua volta for um facilitador desta maternagem (ABRAM, 2000).

Pequenas falhas maternas no atendimento das necessidades do bebê começam a surgir com o passar do tempo, período denominado de dependência relativa por Winnicott. $\mathrm{O}$ bebê passa a ter um maior contato com a realidade compartilhada, que deve ser apresentada pela mãe em pequenas doses. Assim, ele percebe o que é eu e não-eu, desiludindo-se gradativamente. A vivência inicial do período de onipotência é que possibilita ao bebê suportar as frustrações da desilusão de perceber que os objetos que, ilusoriamente, acreditava ter criado são independentes e pertencem ao não-eu, segundo Lapastini (2001). Cabe-nos ressaltar que falhas repetidas e/ou graves na dependência relativa levam ao que Winnicott chamou de de-privação ${ }^{7}$ (ABRAM, 2000).

Para lidar com a realidade externa, inicialmente o bebê busca um objeto externo que substitua a mãe e que seja ao mesmo tempo parte de seu mundo interno. Este fato demonstra a capacidade do bebê em criar o que necessita, remetendo-nos novamente aos estágios iniciais da ilusão. No entanto, este objeto, que não é a mãe, denominado de objeto transicional faz parte da realidade objetiva, mas é percebido pelo bebê de forma subjetiva. Ele é a primeira possessão não-eu do bebê e com o qual ele se relaciona a partir de seu ponto de vista, projetando-se e não levando em conta sua externalidade. Com a segurança que tem na presença real da mãe e da sustentação que esta lhe oferece, o bebê passa a usá-lo (como objeto externo) cessando a projeção. Com o tempo, este objeto é relegado ao limbo (WINNICOTT, 1975).

Falar em sustentação remete-nos às três tarefas maternas: holding, handling e apresentação de objetos. Esta se refere ao oferecimento, pela mãe, de um ambiente constante em que a criança se sinta a vontade para se expressar.

O holding permite ao outro relaxar quanto ao cuidado de si próprio e também a experiência de integração ${ }^{8}$, pois protege o bebê levando em conta sua sensibilidade cutânea - tato, temperatura, sensibilidade auditiva, visual - e sua onipotência. O holding inclui toda a rotina de cuidados oferecidos ao bebê, tanto físicos, quanto psicológicos. Para Winnicott (1983, p. 48), "[...] o holding inclui especificamente o holding/ sustentação física do lactente, que é uma forma de amar. É possivelmente a única forma em que uma mãe pode demonstrar ao lactente seu amor".

Em outras situações de nossa vida podemos observar as funções de holding na forma de cuidados em relação à nossa pessoa, que não ocorrem necessariamente na forma física.

Já o handling envolve o processo de tocar, manipular o bebê durante esses cuidados e, nestes momentos, o cuidador necessita ter a capacidade de identificar o que o bebê necessita. Desta forma, este possibilita que ambos formem uma unidade psicossomática e realiza a junção das partes do bebê para que ele possa caminhar no sentido da integração e formação de um corpo que lhe é próprio (AVELLAR, 2004).

Ao apresentar ao filho objetos do mundo externo, a mãe lhe possibilita a vivência gradativa do mundo compartilhado, a percepção de que não está sozinho e a experiência de onipotência - após a de onipotência inicialmente experimentada pelo bebê. A apresentação de objetos ocorre simultaneamente ao holding e handling, sendo estes eventos indissociáveis (AVELLAR, 2004).

Deve então ser gradativamente que o bebê vai deixando a onipotência e passa a perceber a existência de objetos que não são ele, então deixa de apercebê-

\footnotetext{
${ }^{7} \mathrm{O}$ conceito de de-privação será melhor abordado adiante.

${ }^{8}$ A capacidade de integração se inicia nos primeiros estágios de vida pela relação mãe-bebê. O cuidado dispensado pela mãe ao bebê contribui para que este se sinta uma pessoa no tempo e no espaço (ABRAM, 2000).
} 
los para percebe-los. É para conter a angustia desta percepção e permitir que esse processo de se relacionar objetivamente com o mundo ocorra que surge a transicionalidade - o uso de objetos transicionais. Assim, o bebê sente este objeto como subjetivo, e vai adquirir a capacidade de se relacionar com coisas e pessoas, de maneira a experimentar emoções sem que necessariamente estas representem uma ameaça potencial ou fonte de angústia insuportável (AVELLAR, 2004).

Para Abram (2000) a privação diz respeito a não vivência de algo bom e já a de - privação refere-se ao indivíduo que viveu, em algum momento, algo que é bom e o percebeu como tal, guardando a memória inconsciente de haver sido amado. Quando a criança vive uma experiência de de-privação ela é destituída de um aspecto de sua vida em família, ou seja, há a retirada de algo bom, que é essencialmente positivo ao seu amadurecimento (WINNICOTT, 2000a).

A raiz da tendência antissocial encontra-se na deprivação, pois falhas do ambiente ocorridas durante a dependência relativa terão influências sobre esse sentimento (de serde-privado). Atendência antissocial, portanto, indica que a criança pôde se beneficiar de um ambiente/mãe suficientemente bons em sua fase de dependência absoluta, mas sofreu uma verdadeira de-privação na dependência relativa e por meio de seus atos antissociais busca inconscientemente que o ambiente lhe devolva o que foi perdido e que é seu de direito, busca pelos cuidados vivenciados como suficientemente bons (WINNICOTT, 2000a).

O abandono, não sofrido pela maioria das pessoas, constitui a base da tendência antissocial. A criança perde de vista o objeto e passa a buscá-lo no meio que a deixou só e triste. [...] Acreditamos que possamos entender o comportamento antissocial como um modo de operar em um ambiente que não está sendo suficientemente bom para a criança. Em nossa opinião, a tendência antissocial pode ser vista como uma estratégia de sobrevivência possível da criança em um ambiente privador (SILVA; GREGIO; RIBEIRO, 2011, p. 161).

Winnicott nos diz que a tendência antissocial, assim como a delinquência, implica esperança, e esta compreensão é vital no tratamento de crianças que a apresentam.

Para Abram (2000) o modelo conceitual da tendência antissocial de Winnicott é passível de ser aplicado para aquelas pessoas que não vivenciaram uma constância ambiental em um período decisivo de seu processo de amadurecimento emocional. Este fato é que foi determinante para a escrita deste artigo, a partir das demandas que se apresentam nas unidades de saúde nas quais o projeto de extensão, por um de nós coordenado, atua.

\section{A Inserção da Psicologia nos Serviços Públicos no Brasil}

Para que se possa entender como a saúde mental infantil é tratada nos setores públicos de saúde, é necessário um breve ${ }^{9}$ resgate histórico da própria saúde pública no Brasil e também do conceito de infância.

O Ministério da Saúde admite, conforme Brasil (2005a), que até a década de 70, a história da saúde mental de crianças e adolescentes no Brasil é caracterizada por um grande vazio. Essa lacuna na atenção das políticas de saúde mental para a infância possibilitou a criação de instituições filantrópicas e privadas para o cuidado da infância. Essas instituições, as "psicoclínicas" ou "clínicas de higiene mental", acreditavam que as manifestações patológicas eram resultado de conflitos psicológicos e a patologia mental do

\footnotetext{
${ }^{9}$ Observa-se que esta breve apresentação não pretende traçar uma cronologia exata de acontecimentos, mas destacar fatos significativos para os cuidados que se oferece às crianças atualmente.
} 
adulto como sendo uma repetição de um padrão da infância. Assim, o prognóstico na infância passou a ser visto como uma forma de se prevenir a doença mental no adulto.

De acordo com Monarcha (2009, p. 276), para as psicoclínicas o importante não eram as patologias graves, e sim "os desajustes verificados dentro dos parâmetros da normalidade, por consequência, elas renovaram de maneira surpreendente $o$ interesse e a percepção da infância em situações de aprendizagem e socialização". Era o higienismo da infância e ao mesmo tempo o primeiro olhar para a infância.

Desta forma os saberes científicos, especialmente o pensamento psicológico, legitimou atitudes de exclusão e desqualificação de crianças e jovens pobres e delinquentes, uma vez que fez ou ainda faz recair a terapêutica sobre o indivíduo desviante, esvaziando discussões quanto aos aspectos sociais que compõe o desvio (CRUZ; HILLESHEIM; GUARESCHI, 2005, p. 44).

No governo de Juscelino Kubitscheck (19021976) houve o processo de industrialização acelerado que fortaleceu a economia nos centros urbanos, mas que também gerou uma maior demanda de atendimento pelo sistema de saúde. Cresceu a necessidade de que o Estado interviesse na saúde do trabalhador para manter e restaurar a capacidade de produção. Então, em 1972 foi ampliada a abrangência previdenciária (PAULUS JÚNIOR; CORDONI JÚNIOR, 2006).

Ao mesmo tempo as políticas públicas voltadas ao menor com conduta antissocial se dirigiram para a busca de reeducação e reintegração deste à sociedade por meio de políticas de prevenção, então medidas terapêuticas e de tratamentos educativos, que fossem capazes de evitar que estes se tornassem marginais e representassem riscos à ordem social (CRUZ; HILLESHEIM; GUARESCHI, 2005). Começam aqui as críticas, ainda em acordo com Cruz, Hillesheim e Guareschi (2005, p. 45), quanto às medidas terapêuticas tomadas neste sentido, visto que estas acabaram por produzir práticas de exclusão social que produziam "... menores abandonados, menores de rua, menores em situações de risco social".

Em março de 1986 aconteceu a $8^{\text {a }}$ Conferência Nacional da Saúde. De acordo com Brasil (2005a), o debate trazido pela $8^{\text {a }}$ Conferência ocasionou mudanças constitucionais em relação à criança e ao adolescente, que eram excluídos enquanto sujeitos de direitos:

Resultado de um amplo processo de debate por toda a sociedade brasileira, a promulgação da Carta Constitucional de 1988, marco da democracia e dos direitos, teve o mérito de afirmar sem ressalvas a condição cidadã de crianças e adolescentes [...]. Esse mesmo processo de afirmação da condição de sujeitos de direitos tributado a crianças e adolescentes resultou na promulgação de Lei $\mathrm{n}^{\circ}$ 8.069, de 13/07/1990, conhecida como Estatuto da Criança e do Adolescente (BRASIL, 2005a, p. 8).

Apenas em 1992, a Reforma psiquiátrica atingiu, de acordo com Ferreira (2006, p. 137), “características mais definidas no campo sóciopolítico. [...] quando há uma grande representação dos usuários de serviços em saúde mental questionando o saber psiquiátrico e o dispositivo tecnicista frente a uma realidade que só eles conhecem". Essa representação aconteceu durante a $2^{\text {a }}$ Conferência Nacional de Saúde Mental, sendo que houve o pedido para o fim dos manicômios e foi apontado o quanto era prejudicial a institucionalização de crianças e adolescentes.

Como resultados dessa conferência, os hospitais foram fragmentados, tendo uma maior diversidade de oferta de atendimentos terapêuticos; surgiram os Centros de Atenção Psicossocial (CAPS) com atendimentos diários substituindo os antigos manicômios e; com a preocupação das moradias, surgem as residências terapêuticas. Em outras palavras, foi a partir da Reforma Psiquiátrica que "se constituiu no Brasil a saúde mental no SUS, cuja responsabilidade principal é promover a efetiva substituição do antigo modelo asilar por uma rede de cuidados de base territorial e comunitária" 
(BRASIL, 2005a, p. 9).

Atualmente, essa rede de atenção à saúde é composta por serviços integrados e estabelecidos em uma mesma localização geográfica. Os serviços são divididos em níveis de atenção, sendo eles atenção básica, no nível primário, e os especializados, nos níveis secundário e terciário. Os serviços da rede são: "uma unidade básica de saúde, um hospital geral, um centro de atenção psicossocial, um conselho municipal de saúde, etc.” (BRASIL, 2009, p. 8), sendo estes interligados.

O SUS tem como prioridade a atenção primária em saúde, caracterizada por

"um conjunto de ações de saúde, no âmbito individual
e coletivo, que abrangem a promoção e a proteção
da saúde, a prevenção de agravos, o diagnóstico, o
tratamento, a reabilitação e a manutenção da saúde"
(CONSELHO NACIONAL DE SECRETÁRIOS DE
SAÚDE, 2006, p. 2).

A atenção primária deve proporcionar, assim, um cuidado generalizado, centrado na pessoa e não na doença, além da atenção à família, à comunidade, e o acompanhamento do paciente em outros níveis de atenção, quando isso é necessário. Toda a rede é organizada em torno da atenção primária. São nas ou a partir das Unidades Básicas de Saúde (UBS) que ocorrem grande parte do atendimento à saúde primária.

Segundo Dimenstein (1998, p. 65), passado algum tempo depois da implantação do SUS, "ocorreram mudanças nas políticas de saúde que propiciaram abertura do campo para outros grupos profissionais, além dos médicos", isso inclui a atuação do psicólogo. No entanto, esse profissional vem sentindo dificuldades na realização de seu trabalho nas UBS. Isso ocorre devido a uma limitação na formação do psicólogo, que predominantemente acaba utilizando técnicas psicoterápicas como único instrumento de trabalho.

A implementação das novas políticas públicas direcionadas à saúde mental amplia qualitativamente a participação e controle social sobre a atuação dos profissionais de saúde. Observa-se no município sede do projeto de extensão universitária, já citado e mais bem explicado na sequência deste artigo, aumento do número de profissionais da Psicologia em Unidades Básicas de Saúde e o surgimento do Centro de Apoio Psicossocial (CAPS) no Centro de Atenção Psicossocial do município, como forma de ação antimanicomial e também como resposta às exigências da sociedade por atendimentos públicos direcionados a saúde mental.

As ações da atenção primária e secundária passam a ser valorizadas no referido município. No entanto também se pôde observar a pouca adesão dos profissionais da Psicologia na atenção à criança, priorizando o atendimento de adulto baseando-se ainda em modelos curativos e individualizados de atenção psicológica.

Considera-se que as falhas na atenção à criança denotam uma dificuldade formativa nos profissionais para atuação no campo da atenção à saúde pública. Além desta, observa-se a dicotomização entre o considerado público - os outros - e nós - os profissionais de saúde pública (saúde pública dos outros, portanto). Adorno, Vasconcellos e Alvarenga (2011) propõem um olhar sobre a forma como se relacionam os sujeitos e que define o olhar profissional sobre eles para que se pense, então, sobre o que é o público da saúde pública. O público para estes autores são todos os implicados na saúde coletiva e não somente a população despossuída de riqueza material.

Concomitantemente às ações no campo da saúde pública - o SUS - a assistência social no país possui um sistema, chamado SUAS (Sistema Único de Assistência Social), que organiza e regula todo o aparelho socioassistencial no campo da proteção social do Brasil. Existem dois tipos de proteção social, sendo eles intimamente ligados aos Centros de Referência de Assistência Social (CRAS) e aos Centros de Referência Especializada de Assistência Social (CREAS), que são a proteção social básica e a proteção social especial (BRASIL, 2005b).

A proteção social básica é uma proteção preventiva de situações de risco ligadas a vulnerabilidade social. 
Essa vulnerabilidade está associada, de acordo com BRASIL (2005b, p. 18), à “pobreza, privação (ausência de renda, precário ou nulo acesso aos serviços públicos, dentre outros) e, ou, fragilização de vínculos afetivos - relacionais e de pertencimento social". Os serviços relacionados à proteção social básica são realizados nos CRAS, entre outros espaços da Assistência Social que procuram fazer esta mesma proteção. Os trabalhos do CRAS compreendem o desenvolvimento de projetos, programas e serviços preventivos contra os riscos sofridos pelas pessoas que estão em situações de vulnerabilidade. Cabe enfatizar que esses trabalhos têm função de prevenção ou minimização das desigualdades sociais.

A proteção social especial é destinada àqueles cujos direitos já tenham sido violados. Assim, a proteção social especial atua com famílias ou indivíduos que se encontram em risco por conta de "abandono, maus tratos físicos e, ou, psíquicos, abuso sexual, uso de substâncias psicoativas, cumprimento de medidas socioeducativas, situação de rua, situação de trabalho infantil, entre outras" (BRASIL, 2005b, p. 18). Os serviços executados pela proteção social especial estão, então, ligados com a garantia de direitos dos indivíduos. As atividades desenvolvidas nesse tipo de proteção são realizadas nos CREAS e podem se agrupar na categoria de média ou alta complexidade. As atividades devem ser articuladas entre a Assistência Social, os órgãos de defesa dos direitos e demais políticas públicas.

É importante ressaltar que os psicólogos que atuam nos CRAS e CREAS devem trabalhar no sentido dessas duas proteções já descritas.

O Conselho Federal de Psicologia (CFP), por meio do Centro de Referência Técnica em Psicologia e Políticas Públicas (CREPOP), elaborou, em 2007 e reimprimiu em 2008, uma cartilha pela qual discorre sobre a atuação do psicólogo no CRAS. Assim como já descrito, o Conselho Federal de Psicologia (2008, p. 30) diz que o psicólogo deve "enfatizar as relações da pessoa com seus contextos, atentar para a prevenção das situações de risco e contribuir para as potencialidades pessoais e coletivas". A mesma cartilha expõe que o psicólogo deve atuar em equipe interdisciplinar dentro das normas estabelecidas pela Assistência Social, sendo os casos específicos com demanda de psicoterapia encaminhados para o atendimento em outros pontos da rede pública.

Assim se apresenta novamente a dicotomização dos serviços públicos para o trabalho do psicólogo com a mesma população, pressupondo áreas distintas para sua atuação tratando a psicoterapia como técnica que não serve à assistência social. Talvez se observe aqui a distinção entre o público - coletivo - e o privado - o eu individualizado e separado do coletivo/contexto social. A criança/adolescente com manifestação da tendência antissocial neste direcionamento estaria sendo responsabilizada individualmente por seus atos? Ou seu sofrimento mereceria um olhar outro que não o do social? Há técnicas específicas da psicologia para cada questão do homem que se apresente? Começa-se assim a problematização da questão de manifestação da tendência antissocial.

\section{O projeto de Extensão Universitária "Enquadres Clínicos Winnicottianos na Saúde Pública"}

Observa-se, por meio da atuação de dois dos autores $^{10}$ deste artigo no projeto de extensão universitária citado, crescente aumento de demanda por atendimento psicológico de crianças com comportamentos de birra, enurese, roubo, mentiras e comportamentos classificados por educadores e familiares como inadequados, agressivos e antissociais. Chama atenção ainda

${ }^{10}$ Diana Pancini de Sá Antunes Ribeiro, coordenadora do projeto, e Ana Lucia Volpato, integrante do projeto em 2013. 
a idade cada vez menor das crianças com tais queixas.

Este projeto de extensão está em curso desde o ano de 2000 com a participação de alunos de psicologia que atuam em unidades de saúde, semanalmente. São alunos tanto da graduação, quanto da pósgraduação, mas em sua maioria de graduação. Estes dedicam um período diário semanal para receber demanda de crianças e seus cuidadores com solicitações de atendimento psicológico, espontâneos ou vindos de encaminhamentos diversos (Conselho Tutelar, escolas, entre outros).

São sete as Unidades Básicas de Saúde na qual o projeto se desenvolve. Trabalha-se com uma média de 12 estagiários/ano, de fevereiro a novembro de cada ano e que são supervisionados pela coordenadora do projeto, semanalmente. As crianças e seus cuidadores, em geral mães e/ou avós, passam por cuidadosa avaliação psicológica a partir do sofrimento manifestado por ambos e são encaminhados para atendimento psicoterápicos, para projetos sociais municipais (autarquia de esportes, Fundação de Cultura, entre outros), para outras especialidades ou para atendimentos considerados diferenciados, organizados a partir das demandas apresentadas e 'criados' para acolher estas necessidades. Exemplo de enquadre diferenciado oferecido pelo projeto é a possibilidade de 'Consulta terapêutica domiciliar', que ocorre em casos de doenças orgânicas severas ou outra condição impeditiva para a pessoa se locomover à unidade de saúde.

Com embasamento teórico psicanalítico, especialmente os ensinamentos de Donald W. Winnicot, efetuados a partir de sua prática clínica, enquadres clínicos diferenciados em psicologia com crianças puderam ser trabalhados no contexto da saúde no setor público a partir da avaliação inicial. Deste autor, observa-se que o conceito da tendência antissocial tem estado presente também em vários trabalhos científicos elaborados sobre a experiência clínica neste espaço público (PONCE;
ZANARDO; RIBEIRO, 2010; RIBEIRO; PONCE; TOSONI, 2010; SILVA, GREGIO, RIBEIRO, 2011; ULLIAM, RIBEIRO, 2011).

A prática com o desenvolvimento do projeto demonstrou o desconforto das famílias e/ou dos responsáveis legais das crianças que tem como queixa manifestações de tendência antissocial. Comportamentos destrutivos, mentiras, roubos, entre outros, são popularmente ainda considerados como porta de entrada para a delinquência juvenil. Esta “[...] crença que assusta profundamente a sociedade e devolve à criança um olhar punitivo com o intuito de não permitir o seu temido desajustamento" (SILVA; GREGIO; RIBEIRO, 2011, p. 154). A criança é, então, culpabilizada por seus atos e a causa é, em geral, atribuída a ela própria, como um fator hereditário e como uma sentença a ser cumprida. Consideramos, assim, a importância do conceito, tal como apresentado por Winnicott, pois este devolve ao meio social da criança a responsabilização sobre estas manifestações antissociais.

Os enquadres clínicos advindos da atuação no projeto supracitado se direcionam cada vez mais para ações com os grupos sociais em que as crianças e adolescentes considerados antissociais convivem. Estas ações são condizentes com a proposição de Winnicott que reporta as manifestações de tendência antissocial à de-privação, indicando o fundamental papel do ambiente no processo.

São às famílias, nas mais diversas configurações familiares que se apresentam na atualidade, às escolas, às organizações religiosas, etc., que se direcionam as ações que se nomeiam aqui como 'atenção psicológica' em enquadres diferenciados. Desta forma, além do enquadre já citado anteriormente, em se tratando de prevenção em saúde mental, foram organizados grupos de sala de espera com gestantes e acompanhantes para que os responsáveis pela criança sejam acolhidos pela psicologia desde muito cedo e possam compreender os sentidos do ambiente que oferecem aos seus filhos 
e sua repercussão em seu comportamento. Rodas de conversa em escolas tiveram o mesmo objetivo em relação aos professores e foram organizadas no ensino básico na região de abrangência de uma das unidades de saúde, na qual o projeto se desenvolve. Outro exemplo de atenção psicológica é um grupo, recentemente organizado, de atenção psicológica às mães de recém-nascidos em uma UBS. Há ainda o oferecimento de sessões de atendimento clínico aos responsáveis pela criança em que a temática do ambiente social é trabalhada, sem fins, a priori, denominados terapêuticos.

Enfim, percebe-se a necessidade premente de que se façam ações em psicologia voltadas à prevenção de manifestações de tendência antissocial. A atenção primária é que deve proporcionar um cuidado generalizado, centrado na pessoa e não na doença, além da atenção à família. Deve, portanto, ser mais bem organizada em ações preventivas de natureza outra que não somente o oferecimento, por parte da psicologia, de ações curativas, tais como as psicoterapias. Obviamente, há situações em que esta técnica se faz necessária, mas não em casos de manifestações de tendência antissocial, segundo Winnicott.

As implicações das questões teóricas para as ações, no setor público ou não, em saúde mental e/ ou projetos sociais são, assim, consideradas como de extrema importância. Pretende-se que os sujeitos sejam responsáveis pelos seus atos, manifestem ou não a tendência antissocial. Considera-se, no entanto, que quando se trata de crianças antissociais, deve-se antes conhecer sua história e não dissociá-la da história das pessoas com as quais conviva. Este é um aspecto que se considera essencial, já que a base da tendência antissocial é a de-privação, a perda de um ambiente de holding, de um ambiente suficientemente bom. Como não se trata de uma doença mental, a tendência antissocial solicita outro enquadre de atenção psicológica e em vários níveis (primário, secundário e, em alguns casos, terciário).

\section{Discussão e Considerações Finais}

Ao se considerar o conceito de tendência antissocial tal como proposto por Winnicott e se atrever a considerá-lo para reflexões no campo da atenção do setor público às crianças consideradas antissociais, sabe-se que não se trata de algo inovador. Trabalhos anteriores, inclusive alguns que contaram com participação de um dos autores deste artigo, entre os quais destacamos o de Ponce, Zanardo e Ribeiro (2010), já esboçavam inquietações com crianças assistidas pelos equipamentos de estado. Demonstra-se, portanto que não se pretende esgotar as reflexões sobre esta questão em um artigo.

Pôde-se observar com a incursão pela história da inserção da psicologia no setor público em saúde mental e também nas ações sociais, que esta área da ciência esteve sempre respondendo a uma demanda da ordem socioeconômica, portanto nem sempre avaliando as implicações de todas as personagens envolvidas no surgimento de atos antissociais. Lembre-se que para Winnicott o ambiente deve ser suficientemente bom no trato com os bebês e também nos cuidados oferecidos às crianças, adolescentes e/ou adultos antissociais.

Antes de tudo estes necessitam que os seus cuidadores se voltem para suas necessidades que surgiram a partir de uma de-privação, pois não são doentes ou passíveis de tratamentos apenas individualizados que reportam a eles próprios a responsabilidade de seu sofrimento. Além disso, não podem ser educados, moldados pedagogicamente a partir de referenciais externos. Neste caso é sua necessidade que deverá ser suprida para que ele possa daí espontânea e criativamente, decidir sobre o que aprender e a que responder socialmente.

Tal como se expôs no início deste texto, a psicologia na saúde pública parece repetir um velho erro ao se pautar pela dicotomia entre o que é considerado público - os outros - e nós - os profissionais, em acordo com Adorno, 
Vasconcellos e Alvarenga (2011). Há que se considerar que o público compreende todos e este fato poderá implicar efetivamente os profissionais com a saúde pública e/ou com as ações sociais nas quais a psicologia participa. Como ir ao encontro das necessidades das pessoas com manifestação de tendência antissocial se o psicólogo não se coloca como igual? O psicólogo deve ser sensível às necessidades do de - privado. Como fazê-lo se sua posição for a de não pertencente à mesma categoria de sujeito?

Outro aspecto que se apresenta são ações em várias instâncias públicas sobre sujeitos antissociais que na atualidade permanecem desprotegidos, mas continuam diferenciados na forma de abordagem em duas categorias de sujeitos:

[...] a infância, vitima de abandono, e os menores delinquentes. Essa duplicidade contribui para que os primeiros sejam vistos como vitima passiva, beneficiária de medidas assistencialistas e estigmatizadoras, as quais se confundem com as medidas repressivas aplicadas ao segundo grupo. Ambas as condutas têm mostrado ineficiência, ao longo do tempo, além de perpetuarem a marginalização (RESENDE, 2010, p. 131).

Psicólogos que atuam no setor público não podem ignorar o fato de que suas ações devem ser conjuntas, estar em consonância com as necessidades das pessoas que os procuram em busca de auxílio e não separá-las em "menores", que precisam de correção, e em "crianças", que precisam de proteção (CRUZ; HILLESHEIM; GUARESCHI, 2005, p. 47). Além de ações conjuntas entre profissionais psi, também se deve tratar as ações com todos os profissionais envolvidos e que atuam neste setor para que, de fato, se possa olhar para nós mesmos - o público - e se ocupar das demandas contemporâneas com um olhar inclusivo.

Benevides (2005, p. 24) indica a necessidade também da inseparabilidade entre atenção e gestão, "[...] inseparabilidade entre modos de atender, de cuidar e modo de gerir", que ela própria acrescenta à inseparabilidade entre a clínica e a política".

Considera-se ainda, que as demandas contemporâneas para psicologia estejam em acordo com transformações sociais relativas ao mundo atual que: “[...] apresenta problemas e situações que levam o ser humano a adoecer em sua possibilidade de ser: ele vive hoje fragmentado, descentrado de si mesmo, impossibilitado de encontrar, na cultura, os elementos e o amparo necessários para conseguir a superação de suas dificuldades psíquicas" (SAFRA, 2005, p. 13).

Os atendimentos psicológicos em Unidades Básicas de Saúde, que o projeto de extensão citado atua, possibilitam que se observe que os responsáveis pelas crianças encaminhadas para avaliação se constituem em pessoas adoecidas em sua possibilidade de ser e, portanto, impossibilitados de oferecer às suas crianças um cuidado suficientemente bom. Cuidado este que, muitas vezes, lhes foi possível oferecer no início da vida destas. Como o psicólogo poderá então lidar com este contexto no qual vive a criança/adolescente com manifestação da tendência antissocial? Certamente não poderá excluí-los de sua atenção, pois

[...] o tratamento da tendência antissocial não é a psicanálise. É o provimento de cuidados à criança e nos quais ela pode experimentar de novo os impulsos do id, com possibilidades de testá-lo. É a estabilidade do novo suprimento ambiental que dá a terapêutica. Os impulsos do id devem ser experimentados, para que façam sentido, num quadro de ligação com o ego, e, quando o paciente é uma criança que sofreu privação, a ligação egóica deve obter apoio do lado do relacionamento com o terapeuta [...] é o ambiente que deve dar nova oportunidade à ligação egóica, uma vez que a criança percebeu que foi uma falha ambiental no apoio ao ego que redundou originalmente na tendência antissocial (WINNICOTT, D. 2005b, p. 147).

Para Safra (2005, p. 13) o psicanalista recebe para atendimento na atualidade "[...] um paciente 
com características peculiares, que o obriga a rever continuamente seus pressupostos teóricos e também os procedimentos técnicos utilizados em seu ofício". O psicólogo no setor público também recebe pessoas que procuram ajuda para seu sofrimento, ou seu descompasso com o que é estabelecido socialmente como "normal", que o desafiam a rever seus pressupostos teóricos e procedimentos da sua prática, seja ela clínica ou social.

É neste sentido que se direciona a reflexão para a dicotomização de ações que se propõem a "tratar" da pessoa com manifestações de tendência antissocial. A proposta winnicottiana é que sejam repensados os procedimentos psicológicos para além da psicanálise clássica, de consultório, e que os profissionais se tornem públicos e sensíveis às necessidades desta pessoa, sendo suficientemente bons e indo ao encontro destas necessidades, tal como a mãe ou substituto materno o fazem com seus bebês.

No entanto, resta ainda neste momento uma reflexão em relação à psicologização e psiquiatrização sobre as questões sociais, especialmente no que diz respeito ao tema da violência, também refletida nas pessoas por meio de seus atos antissociais e delinquenciais, que Adorno, Vasconcellos e Alvarenga (2011) propõem. Assim como estes autores não se pretende tratar dessa discussão no espaço deste artigo, mas em acordo com eles:

[...] destacamos a preocupação desse enfoque quando deixe de participar na interpretação da violência o contexto da sociedade, o que acaba por reforçar o dispositivo que destacamos anteriormente: da individualização do fenômeno da violência. [...] De qualquer modo, levantar esses aspectos críticos nos leva a uma situação paradoxal, como mais um "desencaixe" da contemporaneidade (ADORNO; VASCONCELLOS; ALVARENGA, 2011, p. 92).

É certo as possíveis reflexões que este tema possibilita não se esgotaram nesse artigo. Dessa maneira, tal artigo é encerrado com a certeza de que há muitos desafios ainda para os profissionais de psicologia no setor publico de atendimento à saúde mental e no setor da assistência social na contemporaneidade. Tais desafios devem ser problematizados também na formação de psicólogos para uma realidade de saúde pública e social que leve em conta a articulação de problemas do social com a formação de organização coletiva entre autores e vítimas. Esta organização poderá permitir a busca por políticas locais mais inteligentes e menos normativas, tal como nos apontam Adorno, Vasconcellos e Alvarenga (2011).

A formação de psicólogos, portanto, deve se voltar para questões do homem que extrapolem técnicas e teorias vigentes e componham um cenário outro de ações mais aproximadas dos imperativos do homem na contemporaneidade. Este é um dos objetivos do projeto de extensão tomado como ponto de partida, juntamente com o conceito de tendência antissocial, para estas reflexões. Os enquadres clínicos do projeto de extensão, alguns poucos aqui nomeados, buscam este objetivo, qual seja o de se aproximar das demandas contemporâneas para psicologia no setor público de saúde, com um olhar para as necessidades destas demandas. E, ainda, busca formar alunos de psicologia que se coloquem, a partir do importante e fundamental papel que a teoria significa para a condução de suas ações em serviços de saúde, como agentes de saúde que possam extrapolar as técnicas e teorias vigentes, na composição de novos cenários que levem em consideração o homem, seu sofrimento psíquico e suas manifestações, na atualidade.

Finalizamos com as palavras de Benevides (2005, p. 24):

O SUS foi, sem duvida, durante estes anos, o movimento que se firmou como resistência à privatização da saúde. Resistir à privatização, da saúde, da vida é tarefa para muitos, é tarefa para todos nós. Cabe a nós psicólogos, decidir com que movimento nos aliamos, quais movimentos inventamos, quais intercessões fazemos entre a Psicologia e o SUS, entre a Psicologia e as políticas públicas. 


\section{Referências}

ABRAM, J. A Linguagem de Winnicott: dicionário de palavras e expressões utilizadas por Donald W. Winnicott. Rio de Janeiro: Revinter, 2000.

ADORNO, R. C. F.; VASCONCELLO, M. P.; ALVARENGA, A. T. Para viver e pensar além das margens: perspectivas, agenciamentos e desencaixes no campo da saúde pública. Saúde e Sociedade, São Paulo, v. 20, n. 1, p. 86-94, 2011.

AVELLAR, L. Z. A teoria de Winnicott sobre o processo de amadurecimento. In:

Jogando na análise de crianças: intervirinterpretar na abordagem winnicottiana. São Paulo: Casa do Psicólogo, 2004.

BENEVIDES, R. A psicologia e o sistema público de saúde: quais interfaces? Psicologia e Sociedade, Porto Alegre, v. 17, n. 2, p. 21-25, maio/ago. 2005.

BRASIL. Ministério da Saúde. Secretaria de Atenção à Saúde. Caminhos para uma política de saúde mental infanto-juvenil. Brasília, 2005a.

Ministério da Saúde. Secretaria de Atenção à Saúde. Redes de produção de saúde. Brasília, 2009.

Ministério do Desenvolvimento Social e Combate à Fome. Secretaria Nacional de Assistência Social. Norma operacional básica $N O B / S U A S$. Brasília, 2005b.

CONSELHO FEDERAL DE PSICOLOGIA. Centro de Referência Técnica em Psicologia e Políticas Públicas (CREPOP). Referência técnica para atuação $\operatorname{do}(a)$ psicólogo(a) no CRAS/SUAS. Brasília, 2008. Disponível em: $<$ http://crepop.pol.org.br/novo/wp-content/ uploads/2010/11/referenciascras.pdf $>$. Acesso em: 21 jan. 2012.

CONSELHO NACIONAL DE SECRETÁRIOS DE SAÚDE (CONASS). Para entender o pacto pela saúde. 2006. Disponível em: $<\mathrm{http}: / / \mathrm{www}$. conass.org.br/admin/arquivos/NT\%2012-06. pdf $>$. Acesso em: 23 jan. 2012.
CRUZ, L.; HILLESHEIM, B.; GUARESCHI, N. M. F. Infância e políticas públicas: um olhar sobre as práticas psi. Psicologia e Sociedade, Porto Alegre, v. 17, n. 3, p. 42-49, 2005.

DIAS, E. O. A teoria do amadurecimento pessoal. In: - A teoria do amadurecimento de D. W. Winnicott. Rio de Janeiro: Imago, 2009. p. i .f f

DIMENSTEIN, M. D. B. O psicólogo nas unidades básicas de saúde: desafios para a formação e atuação profissionais. Estudos de Psicologia, Natal, v. 3, n. 1, jun., p. 53-81, 1998.

EMÍDIO, T. S. O Pai, a psicanálise e a mitologia: um estudo sobre a função paterna e suas configurações no mundo contemporâneo. 2010. 157f. Tese (Doutorado em Psicologia) - Universidade Estadual Paulista, Assis. Disponível em: <http:// http://polo3.assis.unesp. br/posgraduacao/teses/psicologia/THASSIA. pdf $>$. Acesso em: 12 mar. 2015.

FERREIRA, G. A reforma psiquiátrica no Brasil: uma análise sócio política. Psicanálise e barroco, Rio de Janeiro, v. 4, n. 1, p. 77-85, jun. 2006.

FREUD, S. Dois verbetes de enciclopédia. In: - Edição standard brasileira das obras psicológicas completas de Sigmund Freud. Tradução de Jayme Salomão. Rio de Janeiro: Imago, 1996. v. 18. p. 253-274.

HERRMANN, F. Interpretação: a invariância do método nas várias teorias e práticas clínicas. In: FIGUEIRA, S. A. (Org.). Interpretação: sobre o método da psicanálise. Rio de Janeiro: Imago, 1989 . p. i .-f.

LAPASTINI, M. A. B. Transicionalidade. In: GABRIADES, R.; HISADA, S.; OUTEIRAL, J. (Org.). Winnicott: seminários paulistas. São Paulo: Casa do Psicólogo, 2001. p. i .-f .

MONARCHA, C. Psicoclínicas e cuidados da infância. Boletim Academia Paulista de Psicologia, São Paulo, v. 77, n. 2, p. 274-288, 2009. 
PAULUS JÚNIOR, A.; CORDONI JÚNIOR, L. Políticas públicas de saúde no Brasil. Espaço para a Saúde, Londrina, v. 8, n. 1, p. 13-19, dez. 2006.

PONCE, L. G.; ZANARDO, L. B.; RIBEIRO, D. P. S. Um olhar winnicottiano sobre a violência e a tendência antissocial em crianças e adolescentes em estado de risco psicossocial. In: MATTIOLI, O.; ARAÚJO, M. F.; RESENDE, V. (Org.). $A$ produção da violência na família e nas relações de gênero: estudos e pesquisas. Curitiba: Ed. CRV, 2010. p. 139-149.

RESENDE, A. M. A investigação em psicanálise: exegese, hermenêutica e interpretação. In: SILVA, M. E. L. (Org.). Investigação e psicanálise. Campinas: Papirus, 1993. p. i .-f .

RESENDE, V. Um lugar para a psicanálise no abrigo. In: MATTIOLI, O.; ARAÚJO, M. F.; RESENDE, V. (Org.). A produção da violência na familia e nas relações de gênero: estudos e pesquisas. Curitiba: Ed. CRV, 2010. p. 127-138.

RIBEIRO, D. P. S.; PONCE, L. G.; TOSONI, M. S. Falso-self e manifestação da tendência antissocial: reações do eu ao ambiente não suficientemente bom. In: COLÓQUIO WINNICOTT INTERNACIONAL: o verdadeiro e o falso si-mesmo, 15., 2010, São Paulo. Caderno de resumos... São Paulo: Roseana Moraes Garcia, 2010. p. 29.

SAFRA, G. Introdução. In: . A face estética do self: teoria e clínica. Aparecida: Idéias e Letras, 2005. (Psicanálise século 1).

SILVA, A. F.; GREGIO, S. T.; RIBEIRO, D. P. S. A. Luto e tendência antissocial: a esperança de uma criança. In: ABRÃO, J. L. F.; RIBEIRO, D. P. S. (Org.). A Psicanálise de crianças na universidade: construindo práticas e delimitando fronteiras. São Paulo: Arte e Ciência, 2011. p. 153-167.

ULliAM, E.; RIBEIRO, D. P. S. A. Manejo terapêutico winnicottiano e manifestação de agressividade no setting. In: SIMPÓSIO WINNICOTT DE LONDRINA: teoria e clínica na psicanálise de Winnicott, 2011, Londrina. Caderno de Resumos das Comunicações.... Londrina: UEL, 2011. p. 21.
WINNICOTT, C. Introdução. In: WINNICOTT, D. W. Privação e delinquência. São Paulo: Martins Fontes, 2005.

WINNICOTT, D. W. Agressão e suas raízes. In: - Privação e delinqüência. São Paulo:

Martins Fontes, 2005.

A mãe dedicada comum. In: . Os beb $\hat{e} s$ e suas mães. São Paulo: Martins Fontes, 1996.

. Desenvolvimento emocional primitivo. In:_. Da pediatria à psicanálise. Rio de Janeiro: Imago, 2000.

A preocupação materna primária. In: Da pediatria à psicanálise. Rio de Janeiro: Imago, 2000.

A tendência anti-social. In:

Privação e delinquência. São Paulo: $\overline{\text { Martins }}$ Fontes, 2005.

Objetos transicionais e fenômenos transicionais. In: $\quad O$ brincar $e$ a realidade. Rio de Janeiro: Imago, 1975.

. Teoria do relacionamento paternoinfantil. In: _. O ambiente e os processos de maturaçãão. Porto Alegre: Artes Médicas, 1983.

Recebido em: $12 \mathrm{dez} .2013$ Aceito em: 13 jan. 2015. 